\title{
The natural stilbenoid pinosylvin and activated neutrophils: effects on oxidative burst, protein kinase C, apoptosis and efficiency in adjuvant arthritis
}

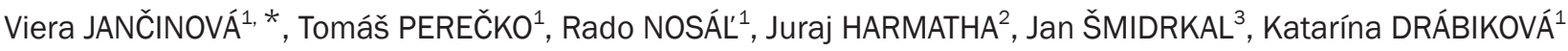 \\ ${ }^{1}$ Institute of Experimental Pharmacology and Toxicology, Slovak Academy of Sciences, Dúbravská cesta 9, 841 04 Bratislava, Slovak \\ Republic; ${ }^{2}$ Institute of Organic Chemistry and Biochemistry, Academy of Sciences of Czech Republic, Flemingovo náměstí 2,16610 \\ Praha 6, Czech Republic; ${ }^{3}$ Institute of Chemical Technology Prague, Faculty of Food and Biochemical Technology, Technická 5, 16628 \\ Praha 6, Czech Republic
}

Aim: To investigate the effects of the naturally occurring stilbenoid pinosylvin on neutrophil activity in vitro and in experimental arthritis, and to examine whether protein kinase C (PKC) activation served as an assumed target of pinosylvin action.

Methods: Fresh human blood neutrophils were isolated. The oxidative burst of neutrophils was evaluated on the basis of enhanced chemiluminescence. Neutrophil viability was evaluated with flow cytometry, and PKC phosphorylation was assessed by Western blotting analysis. Adjuvant arthritis was induced in Lewis rats with heat-killed Mycobacterium butyricum, and the animals were administered with pinosylvin (30 mg/kg, po) daily for $21 \mathrm{~d}$ after arthritis induction.

Results: In isolated human neutrophils, pinosylvin (10 and $100 \mu \mathrm{mol} / \mathrm{L}$ ) significantly decreased the formation of oxidants, both extraand intracellularly, and effectively inhibited PKC activation stimulated by phorbol myristate acetate (0.05 $\mu \mathrm{mol} / \mathrm{L})$. The inhibition was not due to neutrophil damage or increased apoptosis. In arthritic rats, the number of neutrophils in blood was dramatically increased, and whole blood chemiluminescence (spontaneous and PMA-stimulated) was markedly enhanced. Pinosylvin administration decreased the number of neutrophils (from $69671 \pm 5588 / \mu \mathrm{L}$ to $51293 \pm 3947 / \mu \mathrm{L}, P=0.0198$ ) and significantly reduced the amount of reactive oxygen species in blood.

Conclusion: Pinosylvin is an effective inhibitor of neutrophil activity, and is potentially useful as a complementary medicine in states associated with persistent inflammation.

Keywords: pinosylvin; neutrophils; reactive oxygen species; protein kinase C; apoptosis; adjuvant arthritis

Acta Pharmacologica Sinica (2012) 33: 1285-1292; doi: 10.1038/aps.2012.77; published online 30 Jul 2012

\section{Introduction}

Neutrophils (neutrophilic polymorphonuclear leukocytes) represent the body's primary line of defense against invading pathogens. Additionally, they have recently been increasingly studied as active participants in the initiation and progression of many pathological conditions, such as ischaemia-reperfusion injury, gout, lupus, acute respiratory distress syndrome and rheumatoid arthritis. All of these conditions are generally accompanied by dysregulated, persistent and excessive activation of neutrophils, resulting in damage of adjacent tissues by neutrophil "destructive hardware", including reactive oxygen or nitrogen species and proteolytic enzymes ${ }^{[1-4]}$. In rheumatoid arthritis, oxidants can induce cartilage degradation and depo-

\footnotetext{
* To whom correspondence should be addressed.

E-mail viera.jancinova@savba.sk

Received 2012-02-28 Accepted 2012-05-22
}

lymerize hyaluronan and decrease its lubricative properties; furthermore, they can reduce the protective antioxidant and antiproteinase capacity of synovial fluid and thus participate in joint erosion ${ }^{[1,5]}$. Moreover, neutrophils release molecules that can promote inflammation (eicosanoids, chemokines, and cytokines), and the altered recruitment and delayed apoptosis of these cells hinder the resolution of inflammation ${ }^{[2,4]}$.

From this perspective, novel therapeutic strategies to resolve chronic inflammation are expected to inhibit the formation of neutrophil-derived toxic substances, eg, reactive oxygen species, either directly or through enhanced apoptosis. However, inhibition would be directed against extracellularly released oxidants, rather than those formed intracellularly and involved in the initiation of constitutive apoptosis, although the mechanism of radical generation in nonactivated aging neutrophils is not clear ${ }^{[6,7]}$. Pharmacological interference with protein kinase $\mathrm{C}$ (PKC) activity represents a promising method to modulate 
both neutrophil activity and apoptosis. The isoforms PKCa and $\beta$ II stimulate the formation of reactive oxygen species at the level of NADPH oxidase activation (by phosphorylation and translocation of $\mathrm{p} 47^{\text {phox }}$ from the cytosol to membranes ${ }^{[8]}$ ), while PKCa and $\delta$ are involved in antiapoptotic signaling in neutrophils ${ }^{[9,10]}$.

An inhibitory effect on neutrophil function was discovered for several drugs ${ }^{[11]}$ and natural substances ${ }^{[12-17]}$. The latter are particularly useful for their low toxicity and ability to control the activity of neutrophils through several mechanisms. For example, trans-resveratrol (trans-3,4',5-trihydroxystilbene) repressed the adhesion of neutrophils to endothelial cells, the production of reactive oxygen and nitrogen species, and the liberation of elastase and $\beta$-glucuronidase, and it decreased the activities of neutrophil myeloperoxidase and 5- and 15-lipoxygenase (for review see ${ }^{[15]}$ ). Regarding the hydrophilic characteristic of resveratrol, its low bioavailability and rapid clearance from the circulation, attention has been focused on its more lipophilic derivatives ${ }^{[18]}$, such as pinosylvin (trans-3,5dihydroxystilbene, Figure 1).

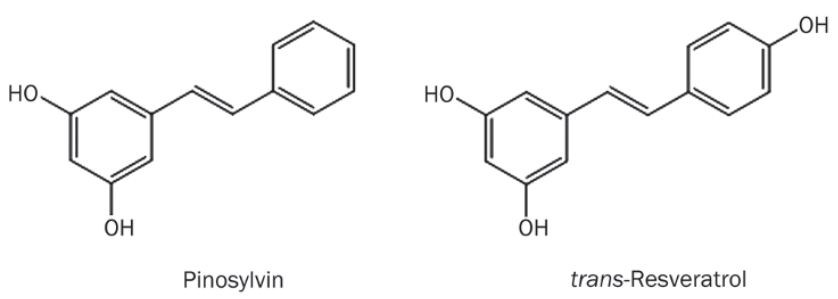

Figure 1. Pinosylvin (trans-3,5-dihydroxystilbene) and its related compound trans-resveratrol (trans-3,4',5-trihydroxystilbene).

This naturally occurring resveratrol analogue is formed constitutively and after UV irradiation or microbial attack in the wood, needles and leaves of Pinus and Alnus species ${ }^{[19]}$. The majority of the data available characterize antifungal, antibacterial and anticancer activities of pinosylvin ${ }^{[20,21]}$; however, little is known about its antioxidant and anti-inflammatory effects $^{[22-24]}$. Previously, we found that pinosylvin improved the effect of methotrexate in experimental arthritis ${ }^{[25,26]}$, and it intensified the reduction in the number and phagocytic activity of neutrophils, hind paw volume and blood oxidant concentration. In the present paper, the impact of pinosylvin on the viability of human neutrophils and formation of reactive oxygen species was investigated, and protein kinase $C$ activation was examined as an assumed target of pinosylvin action. Moreover, in rats with adjuvant arthritis, the efficacy of pinosylvin was assessed in neutrophils modified by inflammation.

\section{Materials and methods}

\section{Chemicals and solutions}

Pinosylvin (trans-3,5-dihydroxystilbene, 98\%) was synthetized and analyzed at the Institute of Organic Chemistry and Biochemistry of the Academy of Sciences of the Czech Republic; details are provided elsewhere ${ }^{[27]}$. Luminol, isolu- minol, PMA (4 $\beta$-phorbol-12 $\beta$-myristate-13a-acetate), the $\mathrm{Ca}^{2+}$ ionophore A23187, superoxide dismutase, dextran (average MW $464 \mathrm{kDa}$ ), zymosan (zymosan A from Saccharomyces cerevisiae), firefly luciferase from Photinus pyralis and D-luciferin sodium salt were purchased from Sigma-Aldrich Chemie (Deisenhofen, Germany); HRP (horseradish peroxidase) and catalase were purchased from Merck (Darmstadt, Germany); and lymphoprep (density $1.077 \mathrm{~g} / \mathrm{mL}$ ) was purchased from Nycomed Pharma AS (Oslo, Norway). Propidium iodide and rh Annexin V-FITC (produced in E coli and conjugated with fluorescein isothiocyanate, FITC) was purchased from Bender MedSystems GmbH (Vienna, Austria). M butyricum in incomplete Freund's adjuvant, which was used for the induction of adjuvant arthritis, was obtained from Difco Laboratories (Detroit, MI, USA).

Pinosylvin administered to arthritic rats was dissolved in sunflower oil at $30 \mathrm{~g} / \mathrm{L}$. For the in vitro studies, pinosylvin $(1.06 \mathrm{mg})$ was dissolved in a mixture of $20 \mu \mathrm{L}$ of $1 \mathrm{~mol} / \mathrm{L}$ $\mathrm{NaOH}$ and $980 \mu \mathrm{L}$ of Tyrode's solution. The stock solution (5 mmol/L) was further diluted with Tyrode's solution to give pinosylvin sample concentrations of $0.1-100 \mu \mathrm{mol} / \mathrm{L}$. The corresponding final concentrations of $\mathrm{NaOH}$ were $0.4-400$ $\mu \mathrm{mol} / \mathrm{L}$; at these concentrations, the solvent agent alone did not reduce the activity or viability of neutrophils. Phosphatebuffered saline (PBS) contained $136.9 \mathrm{mmol} / \mathrm{L} \mathrm{NaCl}, 2.7$ $\mathrm{mmol} / \mathrm{L} \mathrm{KCl}, 8.1 \mathrm{mmol} / \mathrm{L} \mathrm{Na}_{2} \mathrm{HPO}_{4}, 1.5 \mathrm{mmol} / \mathrm{L} \mathrm{KH}_{2} \mathrm{PO}_{4}$, $1.8 \mathrm{mmol} / \mathrm{L} \mathrm{CaCl}_{2}$, and $0.5 \mathrm{mmol} / \mathrm{L} \mathrm{MgCl}_{2}, \mathrm{pH}$ 7.4. Tyrode's solution consisted of $136.9 \mathrm{mmol} / \mathrm{L} \mathrm{NaCl}, 2.7 \mathrm{mmol} / \mathrm{L}$ $\mathrm{KCl}, 11.9 \mathrm{mmol} / \mathrm{L} \mathrm{NaHCO}_{3}, 0.4 \mathrm{mmol} / \mathrm{L} \mathrm{NaH}_{2} \mathrm{PO}_{4} \cdot 2 \mathrm{H}_{2} \mathrm{O}$, $1 \mathrm{mmol} / \mathrm{L} \mathrm{MgCl}_{2} \cdot 6 \mathrm{H}_{2} \mathrm{O}$, and $5.6 \mathrm{mmol} / \mathrm{L}$ glucose, $\mathrm{pH} 7.4$. Binding buffer used in flow cytometric analyses contained 10 $\mathrm{mmol} / \mathrm{L} \mathrm{HEPES}, 140 \mathrm{mmol} / \mathrm{L} \mathrm{NaCl}$, and $2.5 \mathrm{mmol} / \mathrm{L} \mathrm{CaCl}_{2}$, $\mathrm{pH} 7.4$.

\section{Whole blood, buffy coat, and neutrophil isolation}

Fresh human blood was obtained at the blood bank by venipuncture from healthy male donors (20-50 years) who had not received any medication for at least $7 \mathrm{~d}$. The samples were anticoagulated with $3.8 \%$ trisodium citrate (blood to citrate ratio=9:1). Subsequently, the blood was gently mixed with dextran solution ( $1 \%$ final concentration), and erythrocytes were allowed to sediment $(1 \times g)$ at $22^{\circ} \mathrm{C}$ for 25 min. A suspension of leukocytes and platelets in plasma (buffy coat) was used for flow cytometric analyses or for neutrophil isolation. For neutrophil isolation, the buffy coat was centrifuged at $500 \times g$ for $10 \mathrm{~min}$, and the sediment was resuspended in PBS, layered on lymphoprep and centrifuged at $500 \times g$ for $30 \mathrm{~min}$. Contaminating red blood cells were removed by hypotonic lysis ( $3 \mathrm{~mL}$ of ice-cold deionized water followed by $3 \mathrm{~mL}$ of $1.8 \% \mathrm{NaCl}$ and $4 \mathrm{~mL}$ of PBS after $45 \mathrm{~s}$ ). After centrifugation at $500 \times g$ for $10 \mathrm{~min}$, neutrophils in PBS were counted, adjusted to a final concentration of $10^{4}$ cells $/ \mu \mathrm{L}$ and kept on ice. The final suspension of neutrophils contained more than $96 \%$ viable cells, as evaluated by trypan blue exclusion, and was used for a maximum of $2 \mathrm{~h}$ - as long as control chemiluminescence remained constant. 
Neutrophil count was assessed by a Coulter Counter (Coulter Electronics, High Wycombe, England). In whole blood (diluted 500×), erythrocytes were destroyed with a lysing reagent before counting.

\section{Formation of reactive oxygen species}

The oxidative burst of neutrophils was evaluated on the basis of enhanced chemiluminescence ${ }^{[28]}$ in a microtiter plate computer-driven luminometer Immunotech LM-01T (Immunotech, Prague, Czech Republic). The chemiluminescence of whole human blood (diluted 250×) enhanced with luminol (250 $\mu \mathrm{mol} / \mathrm{L})$ was induced with PMA $(0.05 \mu \mathrm{mol} / \mathrm{L})$, opsonized zymosan $(0.5 \mathrm{~g} / \mathrm{L})$ or the $\mathrm{Ca}^{2+}$ ionophore A23187 $(1 \mu \mathrm{mol} / \mathrm{L})$. The chemiluminescence of isolated human neutrophils $\left(5 \times 10^{5}\right)$ was initiated by PMA $(0.05 \mu \mathrm{mol} / \mathrm{L})$ and enhanced with either $5 \mu \mathrm{mol} / \mathrm{L}$ isoluminol (extracellular) or $5 \mu \mathrm{mol} / \mathrm{L}$ luminol in the presence of extracellular scavengers, $100 \mathrm{U} / \mathrm{mL}$ superoxide dismutase and $2000 \mathrm{U} / \mathrm{mL}$ catalase (intracellular). The formation of oxidants was evaluated on the basis of integrated values of chemiluminescence over $1800 \mathrm{~s}$ (isolated neutrophils and A23187-stimulated whole blood) and over $3600 \mathrm{~s}$ (whole blood chemiluminescence initiated with PMA or zymosan).

\section{Western blot analysis}

The phosphorylation of protein kinase C (PKC) isoenzymes $a$ and $\beta$ II was detected as previously described ${ }^{[29]}$. Isolated human neutrophils $\left(5 \times 10^{6}\right)$ were incubated at $37^{\circ} \mathrm{C}$ with pinosylvin for $1 \mathrm{~min}$, stimulated with PMA $(0.15 \mu \mathrm{mol} / \mathrm{L}, 1 \mathrm{~min})$ and rapidly lysed by the addition of solubilization buffer (20 $\mathrm{mmol} / \mathrm{L}$ Tris-HCl, $5 \mathrm{mmol} / \mathrm{L}$ EDTA, $1 \%$ Triton, 10\% glycerol, $10 \mathrm{mmol} / \mathrm{L}$ sodium fluoride, $1 \mathrm{mmol} / \mathrm{L}$ sodium orthovanadate, $200 \mu \mathrm{mol} / \mathrm{L}$ PMSF (phenylmethylsulfonylfluoride), 2 $\mu \mathrm{g} / \mathrm{mL}$ pepstatin, $2 \mu \mathrm{g} / \mathrm{mL}$ leupeptin, and $2 \mu \mathrm{g} / \mathrm{mL}$ aprotinin, $\mathrm{pH}$ 7.4). Then, the samples were sonicated on ice and centrifuged $\left(14000 \times g, 5 \mathrm{~min}, 4^{\circ} \mathrm{C}\right)$ to remove unbroken cells. The supernatant was boiled for 5 min with sample buffer (50 $\mathrm{mmol} / \mathrm{L}$ Tris- $\mathrm{HCl}, 2 \%$ SDS (sodium dodecyl sulphate), 7.5\% glycerol, 2.5\% mercaptoethanol, and $0.01 \%$ bromophenol blue, pH 6.8) and loaded on 9.8\% SDS polyacrylamide gels. Proteins (20 $\mu \mathrm{g}$ per lane) were subsequently separated by electrophoresis and immediately transferred electrophoretically to an Immobilon-P Transfer Membrane (Millipore Corp, Badford, MA, USA). Two strips of each membrane were obtained: one for the detection of PKC (area between 60 and $100 \mathrm{kDa}$ ) and one for the detection of $\beta$-actin (30-60 kDa). $\beta$-Actin was used as an internal control to confirm that equal amounts of cellular protein were present in each lane of the gel. Membrane strips were blocked for 60 min with $1 \%$ bovine serum albumin in Tris-buffered saline (TBS, $20 \mathrm{mmol} / \mathrm{L}$ Tris- $\mathrm{HCl}, 154$ $\mathrm{mmol} / \mathrm{L} \mathrm{NaCl}$ and $0.05 \%$ Tween-20, $\mathrm{pH} 7.5$ ) and subsequently incubated for $60 \mathrm{~min}$ in the presence of the following primary antibodies: phospho-PKC alpha/beta II (Thr638/641) antibody (rabbit anti-human, 1:8000, Cell Signaling Technology, Danvers, MA, USA) or $\beta$-actin antibody (rabbit anti-human, 1:4000, Cell Signaling Technology, Danvers, MA, USA). The membranes were subsequently washed six times (overall time
$40 \mathrm{~min}$ ) with TBS and incubated for $60 \mathrm{~min}$ with the secondary antibody conjugated to horseradish peroxidase (anti-rabbit from donkey, 1:10 000, GE Healthcare Life Sciences, Little Chalfont, UK). After washing, the activity of horseradish peroxidase was visualized using Enhanced Chemiluminescence Western Blotting Detection Reagents (GE Healthcare Life Sciences, Little Chalfont, UK) followed by autoradiography. The bands on the autoradiogram were quantified using the ImageJ program, and the optical density of each PKC band was corrected by the optical density of the corresponding $\beta$-actin band.

\section{Measurement of ATP liberation}

Pinosylvin cytotoxicity was evaluated on the basis of ATP (adenosine triphosphate) liberation measured by the luciferinluciferase chemiluminescence method ${ }^{[29]}$. A suspension of isolated neutrophils ( $30000 /$ sample, $30 \mu \mathrm{L}$ ) and $20 \mu \mathrm{L}$ of Tyrode's solution were incubated with $50 \mu \mathrm{L}$ of pinosylvin $(1-100 \mu \mathrm{mol} / \mathrm{L})$ for $15 \mathrm{~min}$ at $37^{\circ} \mathrm{C}$. Then, $10 \mu \mathrm{L}$ of a mixture of luciferin ( $1.6 \mu \mathrm{g} /$ sample) and luciferase (45000 U/sample) was added, and chemiluminescence was recorded for $60 \mathrm{~s}$. The chemiluminescence of ATP standards (1-500 nmol/L) was measured in each experiment, and ATP concentrations in samples were calculated from the calibration curve. The total ATP content was assessed immediately after the sonication of neutrophils for $10 \mathrm{~s}$.

\section{Apoptosis assay using flow cytometry}

Human plasma buffy coat (see section Whole blood, buffy coat, and neutrophil isolation) diluted with binding buffer $(460 \mu \mathrm{L}$, 200000 neutrophils) was incubated with $10 \mu \mathrm{L}$ of pinosylvin (final concentration 1-100 $\mu \mathrm{mol} / \mathrm{L}$ ) for $10 \mathrm{~min}$ at $37^{\circ} \mathrm{C}$. Subsequently, double staining with Annexin V-FITC $(5 \mu \mathrm{L})$ and propidium iodide $(25 \mu \mathrm{L})$ was performed, and cells were analyzed on the flow cytometer Cytomics FC 500 (Beckman Coulter, Inc, Brea, CA, USA). From the granulocyte area, 5000 cells were gated, and the percentage of early apoptotic (Annexin positive and propidium iodide negative), late apoptotic (double positive) and viable cells (double negative) was determined according to Perečko et $a l^{[14]}$.

\section{Effects of pinosylvin in arthritis}

Adjuvant arthritis was induced in male Lewis rats (160-180 g, Breeding Farm Dobrá Voda, Slovakia) by a single intradermal injection of heat-killed $M$ butyricum $^{[30]}$. The study was performed in compliance with the Principles of Laboratory Animal Care and was approved by the local Ethics Committee and the State Veterinary and Food Administration of the Slovak Republic. Pinosylvin $(30 \mathrm{mg} / \mathrm{kg}$, daily, po) was administered over a period of $21 \mathrm{~d}$ after arthritis induction; control animals (healthy and arthritic) were treated with the solvent agent (sunflower oil). Each group consisted of 10 rats. The total production of oxidants in neutrophils (spontaneous and stimulated with $0.1 \mu \mathrm{mol} / \mathrm{L}$ PMA) was determined on the basis of luminol-enhanced chemiluminescence and presented as the mean integrated values over $3600 \mathrm{~s}$. 


\section{Statistical analysis}

All of the values were given as the mean \pm SEM, and the statistical significance of differences between means was established by Student's $t$-test. $P$ values below 0.05 were considered to be statistically significant.

\section{Results}

Pinosylvin reduced the oxidative burst of human neutrophils measured in whole blood (Figure 2). It inhibited chemiluminescence initiated by the activation of membrane receptors, increased calcium concentration and the stimulation of protein kinase $C$ at the mean effective concentrations of $10.67 \pm 1.07$ $\mu \mathrm{mol} / \mathrm{L}$ (opsonized zymosan), 12.99 $\pm 5.64 \mu \mathrm{mol} / \mathrm{L}(\mathrm{A} 23187)$ and $31.38 \pm 8.25 \mu \mathrm{mol} / \mathrm{L}$ (PMA). For comparison, the respective $\mathrm{EC}_{50}$ values of the related compound resveratrol were $12.80 \pm 0.97 \mu \mathrm{mol} / \mathrm{L}, 24.46 \pm 7.86 \mu \mathrm{mol} / \mathrm{L}$ and $3.72 \pm 0.30 \mu \mathrm{mol} / \mathrm{L}$ (data not shown).

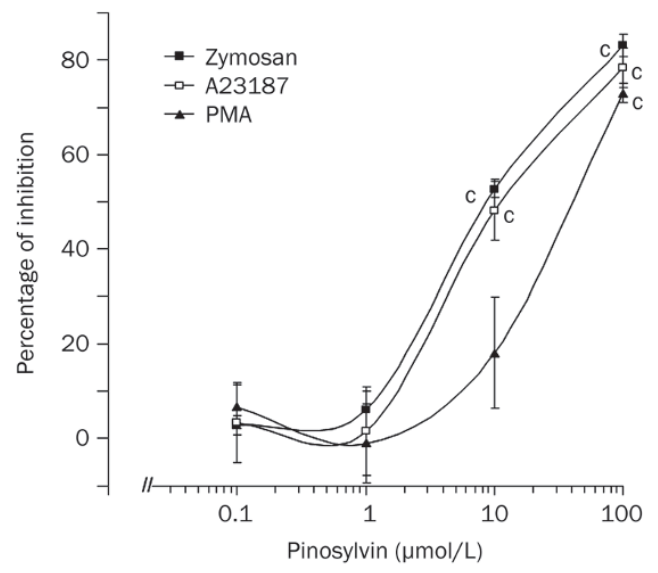

Figure 2. Dose-dependent inhibition of neutrophil chemiluminescence in the presence of pinosylvin. Chemiluminescence, measured in whole blood, was initiated with opsonized zymosan $(0.5 \mathrm{~g} / \mathrm{L}), \mathrm{Ca}^{2+}$ ionophore A23187 (1 $\mu \mathrm{mol} / \mathrm{L})$ or phorbol myristate acetate (PMA, $0.05 \mu \mathrm{mol} / \mathrm{L})$. Mean \pm SEM. $n=6$. ${ }^{\mathrm{C}} P<0.01 \mathrm{vs}$ control. Mean control values of chemiluminescence, given in relative light units - RLU, were $138375 \pm 14776 \mathrm{RLU}$ (zymosan), 26346 $\pm 3386 \mathrm{RLU}$ (A23187), and $1303872 \pm 173251$ RLU (PMA).

In isolated neutrophils stimulated with PMA, extra- and intracellular chemiluminescence was recorded separately. As illustrated in Figures 3 and 4, external oxidant formation was much more intensive and reached maximum values sooner than the oxidative burst arising within neutrophils. Pinosylvin decreased both the extracellular and intracellular chemiluminescence of neutrophils at the respective mean effective concentrations of $14.16 \pm 1.46 \mu \mathrm{mol} / \mathrm{L}$ and $5.54 \pm 1.06 \mu \mathrm{mol} / \mathrm{L}$; the $\mathrm{EC}_{50}$ values assessed for resveratrol were $0.96 \pm 0.22 \mu \mathrm{mol} / \mathrm{L}$ and $6.00 \pm 0.57 \mu \mathrm{mol} / \mathrm{L}$, respectively.

The ability of pinosylvin to inhibit chemiluminescence initiated by different mechanisms and its recorded intracellular activity indicated interference of the neutrophil activation
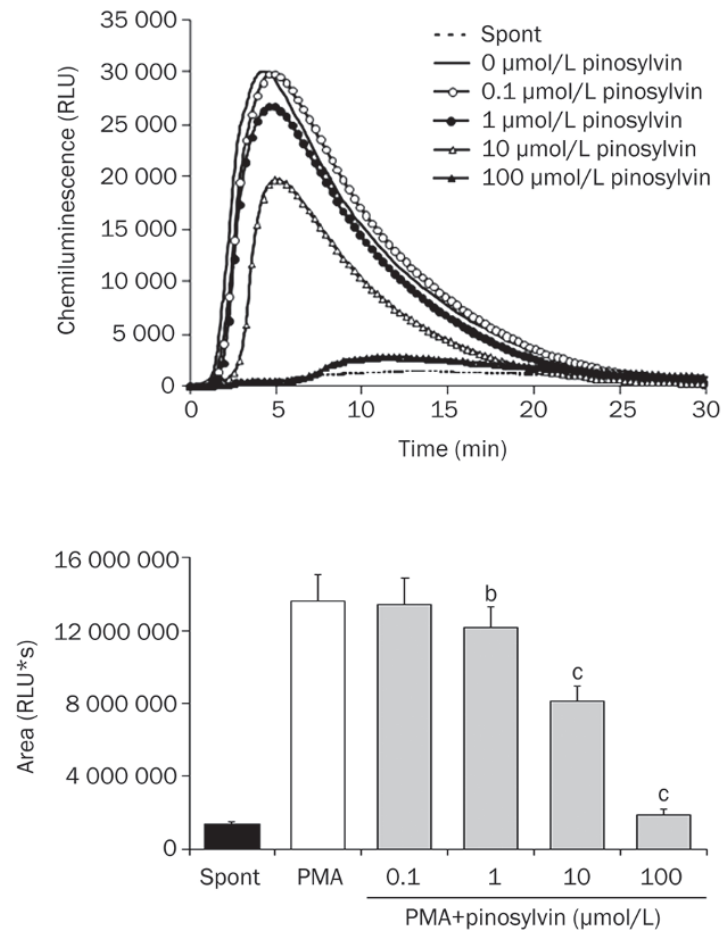

Figure 3. Extracellular chemiluminescence of isolated human neutrophils treated with pinosylvin and stimulated with PMA. Kinetic curves are representative for 6 donors, columns show the mean integral values of chemiluminescence over $1800 \mathrm{~s}$. Mean \pm SEM. $n=6$. ${ }^{b} P<0.05,{ }^{c} P<0.01$ vs PMA. Spont, spontaneous chemiluminescence.

cascade by this phytochemical, particularly with a process involved in the effect of all of the stimuli used. Therefore, the influence of pinosylvin on protein kinase $C$ activation was tested in further experiments. The stimulation of neutrophils with PMA was accompanied by increased phosphorylation of the protein kinase $C$ isoenzymes $\alpha$ and $\beta$ II (Figure 5). Pinosylvin effectively reduced this increase until the values of phosphorylation were comparable with those produced by resting cells.

The observed inhibitory effects were not associated with neutrophil damage because in the presence of pinosylvin no increase in extracellular ATP concentration was recorded (Figure 6). Spontaneous ATP liberation from isolated neutrophils was minimal (approximately 3\% of the total ATP content, as determined immediately after complete neutrophil destruction). This amount remained unchanged (or was slightly decreased) after the treatment of neutrophils with pinosylvin (1-100 $\mu \mathrm{mol} / \mathrm{L})$.

As confirmed by flow cytometry (Figure 7 and Table 1), this stilbenoid did not affect spontaneous apoptosis of human neutrophils. Compared with controls, pinosylvin $(1-100 \mu \mathrm{mol} / \mathrm{L})$ did not alter the percentage of viable, apoptotic or dead neutrophils.

To confirm the efficacy of pinosylvin under inflammatory conditions, whole blood chemiluminescence was analyzed in arthritic rats (Figure 8). Adjuvant arthritis was accompanied 

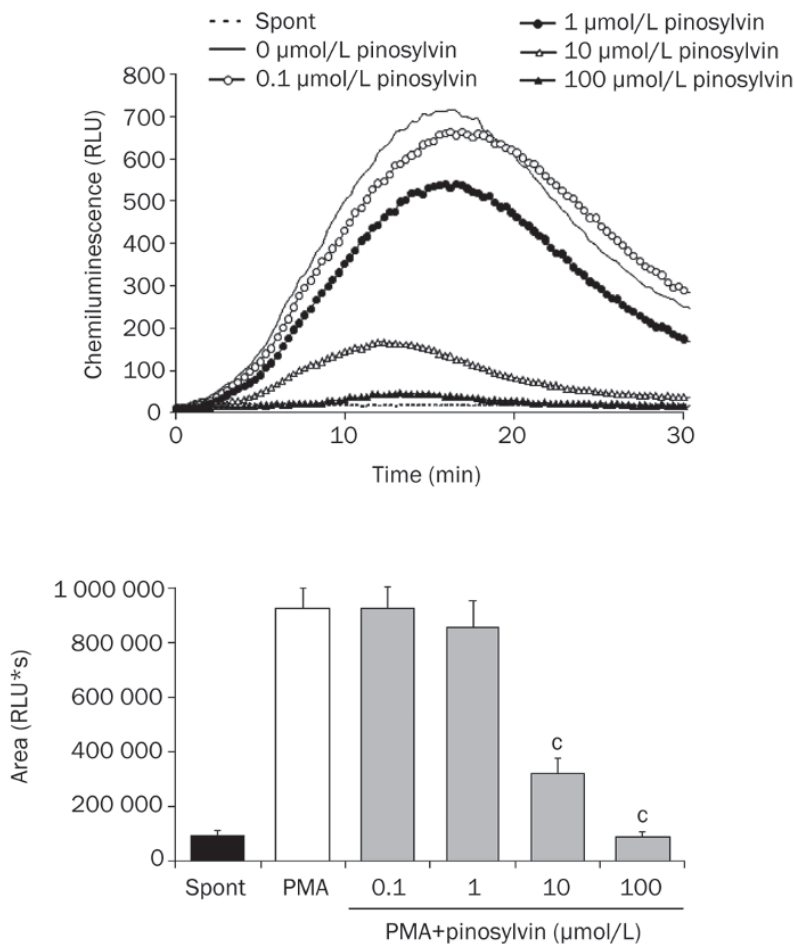

Figure 4. Intracellular chemiluminescence of isolated human neutrophils treated with pinosylvin and stimulated with PMA. Kinetic curves are representative for 6 donors, columns show the mean integral values of chemiluminescence over 1800 s. Mean \pm SEM. $n=6,{ }^{c} P<0.01$ vs PMA. Spont, spontaneous chemiluminescence.
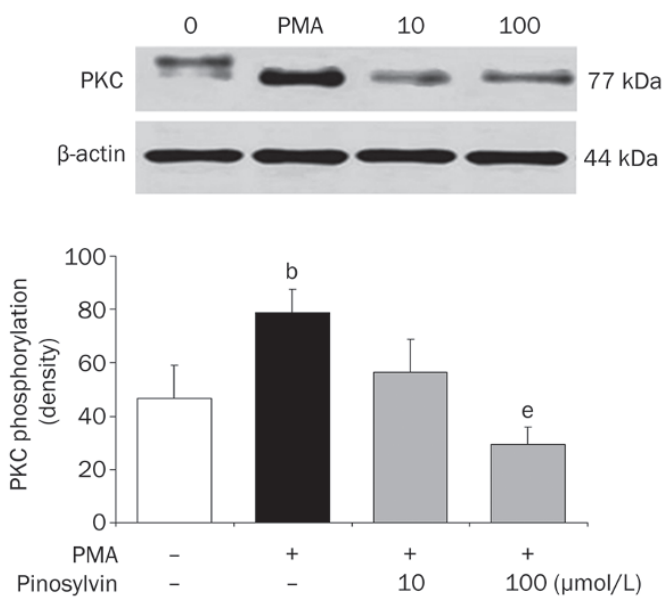

Figure 5. Protein kinase $\mathrm{C}(\mathrm{PKC})$ phosphorylation in PMA stimulated human neutrophils treated with 10 and $100 \mu \mathrm{mol} / \mathrm{L}$ pinosylvin (PIN). The degree of phosphorylation is expressed as optical density of PKC bands corrected to $\beta$-actin content. Phosphorylated PKC isoenzymes $\alpha$ and $\beta I I$ were isolated by Western blotting and detected by phospho-PKC alpha/ beta II (Thr638/641) antibody. Mean \pm SEM. $n=8$ (neutrophils from 4 donors were examined; in each sample protein separation and PKC detection were performed twice - in two separate experiments), ${ }^{b} P<0.05$ vs resting control. ${ }^{\mathrm{e}} \mathrm{P}<0.05$ vs PMA stimulated control. Representative blot manifests elevated phosphorylation of protein kinase $C$ in neutrophils stimulated with PMA, as well as the effect of pinosylvin on this increase.

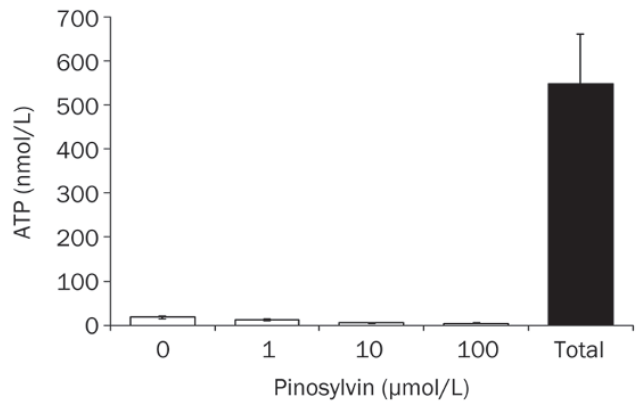

Figure 6. Effect of pinosylvin on the integrity of neutrophil membranes assessed on the basis of ATP liberation. The given values represent the extracellular ATP concentration in samples containing 30000 neutrophils. Open columns - spontaneous ATP liberation in the absence $(0)$ and in the presence of pinosylvin (1-100 $\mu \mathrm{mol} / \mathrm{L})$; Total, amount of ATP determined immediately after complete neutrophil destruction. Mean \pm SEM. $n=8$.
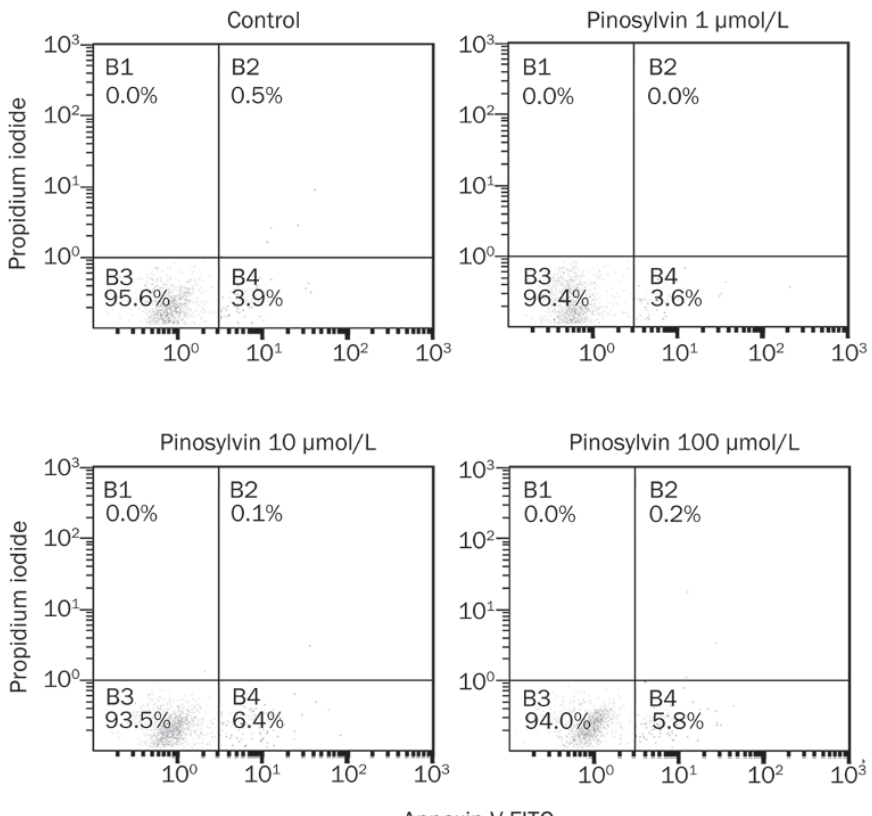

Figure 7. A dot plot of neutrophils stained with propidium iodide and annexin V-FITC indicates cells in three quadrants. Unstained cells are alive and are double negative; they neither express phosphatidylserine on their surface nor do they take up propidium iodide (quadrant B3). Cells stained only with annexin are apoptotic; they have begun to express phosphatidylserine on their surface but have not yet gone through the process that leads to permeabilisation of their cytoplasmic membrane (quadrant B4). Cells stained both with propidium iodide and annexin are necrotic (dead); they take up propidium iodide and also express phosphatidylserine (quadrant B2). Compared to controls, pinosylvin (1$100 \mu \mathrm{mol} / \mathrm{L}$ ) did not alter the percentages of viable, apoptotic and dead neutrophils.

by an increased number of neutrophils in the blood and by more pronounced spontaneous and PMA-stimulated chemiluminescence; all of these changes were reduced by oral administration of pinosylvin. The mean neutrophil count, assessed 
Table 1. Effect of pinosylvin (PIN) on viability and apoptosis of human neutrophils. Mean \pm SEM. $n=8$.

\begin{tabular}{|c|c|c|c|c|}
\hline & Control & PIN $1 \mu \mathrm{mol} / \mathrm{L}$ & PIN $10 \mu \mathrm{mol} / \mathrm{L}$ & PIN $100 \mu \mathrm{mol} / \mathrm{L}$ \\
\hline $\mathrm{AV}^{-} / \mathrm{PI}^{-}$viable cells $(\%)$ & $90.1 \pm 1.6$ & $91.6 \pm 1.2$ & $90.1 \pm 1.0$ & $85.1 \pm 2.9$ \\
\hline $\mathrm{AV}^{+} / \mathrm{PI}^{-}$early apoptotic cells (\%) & $9.5 \pm 1.6$ & $8.0 \pm 1.2$ & $9.4 \pm 0.9$ & $14.2 \pm 2.8$ \\
\hline $\mathrm{AV}^{+} / \mathrm{PI}^{+}$late apoptotic cells (\%) & $0.3 \pm 0.1$ & $0.3 \pm 0.1$ & $0.5 \pm 0.2$ & $0.6 \pm 0.3$ \\
\hline
\end{tabular}

Neutrophil apoptosis was recorded by flow cytometry, using double staining with Annexin-V (A) and propidium iodide (PI).
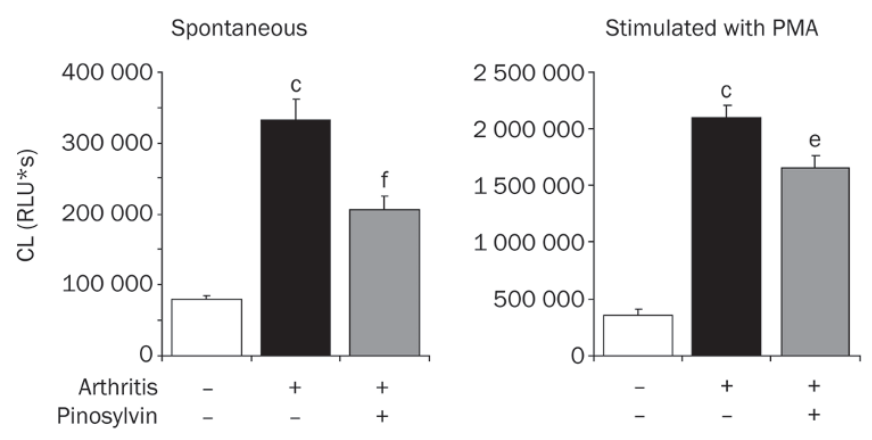

Figure 8. Effect of pinosylvin administration on the formation of reactive oxygen species in adjuvant arthritis. Whole blood chemiluminescence (spontaneous and PMA stimulated) was evaluated on the basis of integral values over $3600 \mathrm{~s}$. Results from three groups of animals are compared - healthy, arthritic without any medication and arthritic animals treated with pinosylvin (30 mg/kg daily, over $21 \mathrm{~d}$ ). Mean \pm SEM. $n=9-10$. ${ }^{\mathrm{c}} P<0.01$ vs healthy control. ${ }^{\mathrm{e}} P<0.05,{ }^{\mathrm{f}} P<0.01$ vs arthritic control.

in $1 \mu \mathrm{L}$ blood, was $16040 \pm 928$ (healthy controls), 69671 \pm 5588 (arthritic animals) and $51293 \pm 3947$ (arthritic rats treated with pinosylvin).

\section{Discussion}

The incubation of human neutrophils with pinosylvin resulted in decreased production of reactive oxygen species. Because the effect occurred in the presence of each stimulus used, the interference of a process involved in all mechanisms of chemiluminescence initiation by pinosylvin has been suggested. One of the potential candidates could be the signaling enzyme protein kinase C. Pinosylvin hindered the activation of this enzyme, as indicated by the decreased phosphorylation of protein kinase $C$ isoenzymes $\alpha$ and $\beta I I$ on their catalytic region. Because these isoenzymes participate directly in the activation of neutrophil NADPH oxidase ${ }^{[8]}$, their inhibition may result in reduced oxidant formation and thus explain the decreased chemiluminescence of neutrophils treated with pinosylvin. Similar to resveratrol, a compound related to pinosylvin, protein kinase $\mathrm{C}$ inhibition may result from the competition for phorbol ester binding to the $\mathrm{C} 1$ domains of the enzyme ${ }^{[31]}$.

Involvement of other mechanisms in the inhibition of chemiluminescence, such as reduced activity of phosphatidylinositol 3-kinase, 5-lipoxygenase, cyclooxygenase, or myeloperoxidase ${ }^{[15,22]}$, cannot be excluded. However, the repressed expression of NADPH oxidase, which was observed in macrophages treated for 3-6 h with resveratrol ${ }^{[32]}$, seems to be unlikely with respect to the early onset of the pinosylvin effect.

Similarly, the antioxidative activity of pinosylvin may be involved to a lesser extent, because both pinosylvin hydroxyl groups are located in the meta position (with respect to the ethylene bridge of the stilbene molecule), $i e$, in an arrangement that is less favorable for both electron abstraction and the distribution of the unpaired electron ${ }^{[18,33]}$. The assessment of lipid peroxyl radical formation ${ }^{[34]}$ and the measurement of human low-density lipoprotein peroxidation ${ }^{[35]}$ confirmed pinosylvin to be a less potent scavenger than resveratrol. Nevertheless, regarding the inhibition of chemiluminescence, we found the activities of these two stilbenoids comparable (eg, in neutrophils stimulated with zymosan or the $\mathrm{Ca}^{2+}$ ionophore A23187), suggesting that radical scavenging may not be a decisive mechanism of pinosylvin action.

Because activated neutrophils form and liberate reactive oxygen species both extra- and intracellularly ${ }^{[36]}$, it was important to identify which part of the chemiluminescence signal was reduced in the presence of pinosylvin. This stilbenoid was found to be active in both compartments. Radicals formed within neutrophils, which are involved in the redox regulation of signal transduction in neutrophils ${ }^{[3]}$, were reduced more effectively than extracellular oxidants.

The decreased chemiluminescence and inhibited formation of oxidants were not associated with altered neutrophil viability. As shown by the measurement of ATP liberation and the cytometric determination of apoptosis, pinosylvin did not reduce the viability of neutrophils at concentrations up to 100 $\mu \mathrm{mol} / \mathrm{L}$. This result contrasted with its cytotoxic and repressive effect assessed in bacteria, fungi and cancer cells ${ }^{[20,21]}$ and with the initiation of apoptosis via activation of caspases, which was observed in the presence of other resveratrol derivatives $^{[37]}$.

The efficacy of pinosylvin was further assessed in neutrophils modified by inflammation.

Adjuvant arthritis, a rat model, mimics the immunological and biochemical features of human rheumatoid arthritis. As revealed in the presented experiments, the number of neutrophils increased more than fourfold in adjuvant arthritis, and this increase was accompanied by an elevated concentration of oxidants in the blood. The assessment of chemiluminescence produced by one neutrophil confirmed that neutrophils of arthritic rats responded excessively to PMA stimulation and synthesized more radicals than neutrophils of healthy controls. A similar priming of peripheral neutrophils was observed in 
patients with rheumatoid arthritis ${ }^{[38-40]}$. These alterations were ascribed to the direct effect of proinflammatory cytokines on neutrophil NADPH oxidase activity, which was induced by the increased phosphorylation of $\mathrm{p} 47^{\text {phox }}$, extracellular signal-regulated kinase, and p38 mitogen-activated protein kinase $^{[39,41]}$.

Orally administered pinosylvin simultaneously decreased the concentration of oxidants and the number of neutrophils, indicating that the beneficial antioxidative effect of this stilbenoid may arise from reduced arthritic neutrophilia (and repressed inflammation) rather than its direct interference with neutrophil activity. The anti-inflammatory activity of pinosylvin, as manifested by reduced hind paw swelling ${ }^{[42]}$, could be ascribed to several mechanisms, such as the reduced synthesis and release of pro-inflammatory mediators, modified eicosanoid synthesis, decreased activity of immune cells and suppressed activation of nuclear factor $\mathrm{KB}^{[22-24,43]}$. Moreover, resveratrol and a-viniferin, compounds that are structurally related to pinosylvin, were found to induce apoptosis of human rheumatoid arthritis synovial cells ${ }^{[44]}$ and prevent tissue destruction in model arthritis ${ }^{[45]}$. Finally, the action of pinosylvin might involve decreased expression of inducible NO synthase and reduced formation of nitric oxide, as found in macrophages ${ }^{[26,46]}$. This effect may prove beneficial because nitric oxide, if transformed into highly reactive peroxynitrite, can activate proinflammatory signaling ${ }^{[47]}$ and contribute to the pathogenesis of arthritis ${ }^{[48]}$.

\section{Conclusion}

Pinosylvin decreased the concentration of oxidants released by activated neutrophils into the extracellular space and the oxidative burst occurring within neutrophils. The inhibition was accompanied by inhibited activation of protein kinase C and the formation of reactive oxygen species in neutrophils. Pinosylvin administered orally reduced the neutrophil count and decreased the concentration of oxidants in the blood of arthritic rats. The observed effects classified pinosylvin as an effective inhibitor of neutrophil activity, which may make it potentially useful as a complementary medicine in pathological states associated with persistent inflammation.

\section{Acknowledgements}

We wish to thank Ing Danica MIHALOVA and Mrs Denisa KOMENDOVÁ for their kind assistance and Prof Magda KOUŘILOVÁ-URBANCZIK for English language correcting. The study was supported by grants APVV-0315-07, APVV-0052/10, VEGA-2/0003/10, VEGA-2/0045/11, and GACR-203/07/1227.

\section{Author contribution}

Viera JANČINOVÁ, Tomáš PEREČKO, and Katarína DRÁBIKOVÁ contributed to the experimental planning and design, performed the experiments, analyzed and interpreted data, and drafted the manuscript; Rado NOSÁL' conceived the study and coordinated and supervised the experiments; Juraj HARMATHA and Jan ŠMIDRKAL participated in study con- ception and synthesized and analyzed pinosylvin.

\section{References}

1 Cascao R, Rosário HS, Fonseca JE. Neutrophils: warriors and commanders in immune mediated inflammatory diseases. Acta Reumatol Port 2009; 34: 313-26.

2 Cascao R, Rosário HS, Souto-Carneiro MM, Fonseca JE. Neutrophils in rheumatoid arthritis: More than simple final effectors. Autoimmun Rev 2010; 9: 531-5.

3 Fialkow L, Wang Y, Downey GP. Reactive oxygen and nitrogen species as signaling molecules regulating neutrophil function. Free Rad Biol Med 2007; 42: 153-64.

4 Wright HL, Moots RJ, Bucknall RC, Edwards SW. Neutrophil function in inflammation and inflammatory diseases. Rheumatology 2010; 49: 1618-31.

5 Edwards SW, Hallett MB. Seeing the wood for the trees: the forgotten role of neutrophils in rheumatoid arthritis. Immunol Today 1997; 18: 320-4.

6 El Kebir D, Filep JG. Role of neutrophil apoptosis in the resolution of inflammation. ScientificWorldJournal 2010; 10: 1731-48.

7 Luo HR, Loison F. Constitutive neutrophil apoptosis: Mechanisms and regulation. Am J Hematol 2008; 83: 288-95.

8 Fontayne A, Dang PMC, Gougerot-Pocidalo MA, El Benna J. Phosphorylation of $p 47^{\text {phox }}$ sites by PKC $\alpha, \beta I I, \delta$, and $\zeta$ : Effect on binding to $2^{22^{\text {phox }}}$ and on NADPH oxidase activation. Biochmistry 2002; 41: 7743-50.

9 Webb PR, Wang KQ, Scheel-Toellner D, Pongracz J, Salmon M, Lord JM. Regulation of neutrophil apoptosis: A role for protein kinase $C$ and phosphatidylinositol-3-kinase. Apoptosis 2000; 5: 451-8.

10 Kilpatrick LE, Sun S, Mackie DM, Baik F, Li H, Korchak HM. Regulation of TNF mediated antiapoptotic signaling in human neutrophils: role of ס-PKC and ERK1/2. J Leukoc Biol 2006; 80: 1512-21.

11 Burgos RA, Hidalgo MA, Figueroa CD, Conejeros I, Hancke JL. New potential targets to modulate neutrophil function in inflammation. Mini-Rev Med Chem 2009; 9: 153-68.

12 Drábiková K, Perečko T, Nosál' R, Bauerová K, Poništ S, Mihalová D, et al. Glucomannan reduces neutrophil free radical production in vitro and in rats with adjuvant arthritis. Pharmacol Res 2009; 59: 399-403.

13 Nosál' R, Perečko T, Jančinová V, Drábiková K, Harmatha J, Sviteková $\mathrm{K}$. Naturally appearing $\mathrm{N}$-feruloylserotonin isomers suppress oxidative burst of human neutrophils at the protein kinase $\mathrm{C}$ level. Pharmacol Rep 2011; 63: 790-8.

14 Perečko T, Drábiková K, Račková L, Číž M, Podborská M, Lojek A, et al. Molecular targets of the natural antioxidant pterostilbene: effect on protein kinase $\mathrm{C}$, caspase- 3 and apoptosis in human neutrophils in vitro. Neuro Endocrinol Lett 2010; 31: 84-90.

15 Alarcón de la Lastra C, Villegas I. Resveratrol as an anti-inflammatory and anti-aging agent: Mechanisms and clinical implications. Mol Nutr Food Res 2005; 49: 405-30.

16 Wu PF, Zhang Z, Wang F, Chen JG. Natural compounds from traditional medicinal herbs in the treatment of cerebral ischemia/ reperfusion injury. Acta Pharmacol Sin 2010; 31: 1523-31.

17 Fei R, Fei Y, Zheng S, Gao YG, Sun HX, Zeng XL. Purified polysaccharide from Ginkgo biloba leaves inhibits P-selectin-mediated leucocyte adhesion and inflammation. Acta Pharmacol Sin 2008; 29: 499-506.

18 Fan GJ, Liu XD, Qian YP, Shang YJ, Li XZ, Dai F, et al. 4,4'-Dihydroxytrans-stilbene, a resveratrol analogue, exhibited enhanced antioxidant activity and cytotoxicity. Bioorg Med Chem 2009; 17: 2360-5.

19 Ludwiczuk A, Saha A, Kuzuhara T, Asakawa Y. Bioactivity guided 
isolation of anticancer constituents from leaves of Alnus sieboldiana (Betulaceae). Phytomedicine 2011; 18: 491-8.

20 Lee SK, Lee HJ, Min HY, Park EJ, Lee KM, Ahn YH, et al. Antibacterial and antifungal activity of pinosylvin, a constituent of pine. Fitoterapia 2005; 76: 258-60.

21 Roupe KA, Remsberg CM, Yáňez JA, Davies NM. Pharmacometrics of stilbenes: Seguing towards the clinic. Curr Clin Pharmacol 2006; 1: 81-101.

22 Adams M, Pacher T, Greger H, Bauer R. Inhibition of leukotriene biosynthesis by stilbenoids from Stemona species. J Nat Prod 2005; 68: 83-5.

23 Lee J, Jung E, Lim J, Lee J, Hur S, Kim SS, et al. Involvement of nuclear factor-kappaB in the inhibition of pro-inflammatory mediators by pinosylvin. Planta Med 2006; 72: 801-6.

24 Park EJ, Min HY, Ahn YH, Bae CM, Pyee JH, Lee SK. Synthesis and inhibitory effects of pinosylvin derivatives on prostaglandin $E_{2}$ production in lipopolysaccharide-induced mouse macrophage cells. Bioorg Med Chem Lett 2004; 14: 5895-58.

25 Bauerová K, Poništ S, Dráfi F, Mihalová D, Paulovičová E, Jančinová $\mathrm{V}$, et al. Study of combination of pinosylvin and methotrexate in the model of adjuvant arthritis: Beneficial effect on clinical and nonclinical parameters. Interdisc Toxicol 2010; 3: 32.

26 Jančinová V, Nosál' R, Lojek A, Čǐz M, Ambrožová G, Mihalová D, et al. Formation of reactive oxygen and nitrogen species in the presence of pinosylvin - an analogue of resveratrol. Neuro Endocrinol Lett 2010; 31: $79-83$.

27 Šmidrkal J, Harmatha J, Buděšínský M, Vokáč K, Zídek Z, Kmoníčková $\mathrm{E}$, et al. Modified approach for preparing (E)-Stilbenes related to resveratrol, and evaluation of their potential immunobiological effects. Collect Czech Chem Commun 2010; 75: 175-86.

28 Číž M, Pavelková M, Gallová L, Králová J, Kubala L, Lojek A. The influence of wine polyphenols on reactive oxygen and nitrogen species production by murine macrophages RAW 264.7. Physiol Res 2008; 57: 393-402.

29 Jančinová V, Perečko T, Nosál' R, Koštálová D, Bauerová K, Drábiková K. Decreased activity of neutrophils in the presence of diferuloylmethane (curcumin) involves protein kinase $\mathrm{C}$ inhibition. Eur J Pharmacol 2009; 612: 161-6.

30 Bauerová K, Poništ S, Mihalová D, Dráfi F, Kuncírová V. Utilization of adjuvant arthritis model for evaluation of new approaches in rheumatoid arthritis therapy focused on regulation of immune processes and oxidative stress. Interdisc Toxicol 2011; 4: 33-9.

31 Slater SJ, Seiz JL, Cook AC, Stagliano BA, Buzas CJ. Inhibition of protein kinase $C$ by resveratrol. Biochim Biophys Acta 2003; 1637: 59-69.

32 Park DW, Baek K, Kim JR, Lee JJ, Ryu SH, Chin BR, et al. Resveratrol inhibits foam cell formation via NADPH oxidase 1-mediated reactive oxygen species and monocyte chemotactic protein-1. Exp Mol Med 2009; 41: 171-9.

33 Queiroz AN, Gomes BAQ, Moraes WM, Borges RS. A theoretical antioxidant pharmacophore for resveratrol. Eur J Med Chem 2009;
44: 1644-9.

34 Stojanovic S, Sprinz H, Brede O. Efficiency and mechanism of the antioxidant action of trans-resveratrol and its analogues in the radical liposome oxidation. Arch Biochem Biophys 2001; 391: 79-89.

35 Cheng JC, Fang JG, Chen WF, Zhou B, Yang L, Liu ZL. Structure-activity relationship studies of resveratrol and its analogues by the reaction kinetics of low density lipoprotein peroxidation. Bioorg Chem 2006; 34: $142-57$.

36 Karlsson A, Dahlgren C. Assembly and activation of the neutrophil NADPH oxidase in granule membranes. Antioxid Redox Signal 2002; 4: 49-60.

37 Li H, Wu WK, Zheng Z, Che CT, Yu L, Li ZJ, et al. 2,3',4,4',5'-Pentam ethoxy-trans-stilbene, a resveratrol derivative, is a potent inducer of apoptosis in colon cancer cells via targeting microtubules. Biochem Pharmacol 2009; 78: 1224-32.

38 Fairhurst AM, Wallace PK, Jawad AS, Goulding NJ. Rheumatoid peripheral blood phagocytes are primed for activation but have impaired Fc-mediated generation of reactive oxygen species. Arthritis Res Ther 2007; 9: R29.

39 Inaba M, Takahashi T, Kumeda Y, Kato T, Hato F, Yutani Y, et al. Increased basal phosphorylation of mitogen-activated protein kinases and reduced responsiveness to inflammatory cytokines in neutrophils from patients with rheumatoid arthritis. Clin Exp Rheumatol 2008; 26: 52-60.

40 Miesel R, Hartung R, Kroeger $\mathrm{H}$. Priming of NADPH oxidase by tumor necrosis factor alpha in patients with inflammatory and autoimmune rheumatic diseases. Inflammation 1996; 20: 427-38.

41 Dang PM, Stensballe A, Boussetta T, Raad H, Dewas C, Kroviarski Y, et al. A specific $p 47^{\text {phox }}$-serine phosphorylated by convergent MAPKs mediated neutrophil NADPH oxidase priming at inflammatory sites. J Clin Invest 2006; 116: 2033-43.

42 Mihalová D, Poništ S, Bauerová K, Nosál' R, Jančinová V. Comparative study of two stilbene derivatives in the experimental rat model of arthritis based on evaluation of clinical parameters. Interdisc Toxicol 2010; 3: 67.

43 Park EJ, Ahn YH, Pyee JH, Park HJ, Chung HJ, Min HY, et al. Suppressive effects of pinosylvin, a natural stilbenoid, on cyclooxygenase-2 and inducible nitric oxide synthase and the growth inhibition of cancer cells. Proc Amer Assoc Cancer Res 2005; 46: 176.

44 Nakayama H, Yaguchi T, Yoshiya S, Nishizaki T. Resveratrol induces apoptosis MH7A human rheumatoid arthritis synovial cells in a sirtuin 1-dependent manner. Rheumatol Int 2012; 32: 151-7.

45 Lee JY, Kim JH, Kang SS, Bae CS, Choi SH. The effects of alphaviniferin on adjuvant-induced arthritis in rats. Am J Chin Med 2004; 32: 521-30.

46 Harmatha J, Zídek Z, Kmoníčková E, Šmidrkal J. Immunobiological properties of selected natural and chemically modified phenylpropanoids. Interdisc Toxicol 2011; 4: 5-10.

47 Gao Y. The multiple actions of NO. Eur J Physiol 2010; 459: 829-39.

48 Abramson SB. Nitric oxide in inflammation and pain associated with osteoarthritis. Arthritis Res Ther 2008; 10: S2. 